\title{
UN ENCUENTRO CON LAS ÁNIMAS; santos y héroes impugnadores de normas
}

\author{
Gloria InÉs PeLÁEz \\ INVESTIGADORA INDEPENDIENTE \\ gloines@tutopia.com
}

Resumen

- L CEMEnterio Central de Bogotá, un Sitio numinoso caracterizado POR LA [ ambivalencia entre el terror y la fascinación, da lugar a la práctica de ritos que pretenden manipular la fuerza de lo sobrenatural. Allí los creyentes se comunican con las ánimas y adquieren de ellas favores, así como un descanso a sus angustias y preocupaciones. Este espacio, lugar también de identidad e historia, es centro de creación de personajes que se revelan milagrosos y cuyas vidas nos muestra implícito el modelo arquetípico del héroe. Con una simbología en la que la presencia de lo femenino está equiparada a la muerte, a la protección, a la resurrección y las prácticas mágicas, las celebraciones del cementerio encuentran en la mujer su principal aliada. Reelaborando sus propias vidas y experiencias, los creyentes confieren existencia a sus milagrosos.

\begin{abstract}
T he Central CEMETERY in BOGOTÁ is a NUMINOUS PLACE WHERE THE AMBIVAlence that characterizes this state of terror and fascination give place to the practice of rituals that pretend to manipulate the force of the supernatural. Here the believers communicate with the souls and acquire from them favors, and relief with their anguish and worries. This space, also a place of identity and history, is at the center of the creation of characters that reveal miraculous, whose lives implicitly show the archetypal model of the hero. With a symbology where the presence of the feminine is equated with death, protection, resurrection, and with magical practices, the celebrations in the cemetery find in women their best ally. By re-elaborating their own lives and experiences, the believers give existence to the miraculous.
\end{abstract}




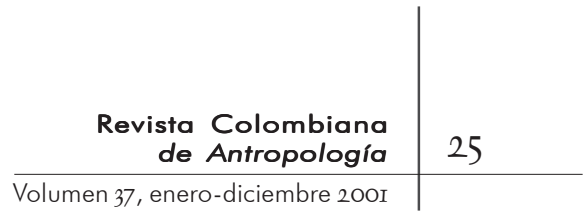

El Cementerio, un miCrocosmos soCial

D ocos lugares poseen tanto VAlOR Simbólico en Bogotá como el cementerio Central. Este lugar, habitualmente considerado un espacio reservado a prácticas religiosas, es también un centro de creación mítica donde se recrean y resuelven penosas situaciones de vida de sus fieles, dando lugar a un imaginario propio de los sectores sociales que lo visitan y se lo apropian con sus ritos y celebraciones. De esta manera, la ciudad y la sociedad en su conjunto pueden verse inscritas en las representaciones y prácticas del cementerio, como contexto y como texto, porque en sus ritos no sólo está presente el universo religioso, lo están la política, el trabajo, las relaciones familiares y el mundo inmediato de sus visitantes. Por ser el más antiguo de la ciudad, este cementerio se constituye en un lugar de identidad e historia. Los monumentos funerarios que se encuentran allí son de gran importancia en la creación de rituales, mantienen viva la memoria de los personajes que en ellos yacen y representan, convirtiéndose así en un patrimonio de la historia nacional. La edificación y conmemoración de este patrimonio se encuentran asociados con el proceso de constitución del estado y la nación (Calvo, I998: XVIII).

El imaginario político originado por el patrimonio histórico se construye a partir de las acciones de las clases en el poder y del legado de este sector de la sociedad, que habla de sus héroes y sus hazañas, erigiéndose como patrimonio de todos, enmarcando los productos históricos y culturales de otros grupos sociales, dominados o excluidos (Calvo, I998). Si bien, como dice Calvo, existe una apropiación desigual de la memoria del país, el cementerio, visitado por amplios sectores populares, confiere sentido de pertenencia e identidad, ya que en él los fieles reconocen y construyen referentes comunes que los abocan a un pasado nacional que ven lejano e inasequible pero del que se apropian por medio de los ritos y su presencia, participando como testigos y como actores de los acontecimientos, llegando incluso a crear sus propios santos destacando sus condiciones de vida como referentes para la sacralización de algunos difuntos, cual es el caso de Salomé, que se trata más adelante.

Cuando los devotos se detienen a rezar frente a las tumbas de reconocidos personajes de la vida nacional, fallecidos en circunstancias violentas, no falta quién pregunte la identidad del 
difunto ni el que cuente su historia: un relato corto que resalta la actividad política de éste y su desdichado final. A estas historias se añaden relatos de orden personal asociados a la vida del personaje famoso; anécdotas de la vida del devoto que de alguna manera conectan con los recuerdos del muerto; datos que tienen que ver con el sitio donde vivían, el día que lo conocieron personalmente o con el conocimiento sobre la familia de sus asesinos. De esta manera actúan ampliando la memoria colectiva, participando de su elaboración e incorporando sus vidas dentro del recuerdo. Mediante los ritos y la comunicación que se establece por medio de la palabra, el contacto con las lápidas y las ofrendas se da una relación de continuidad con el personaje, entre el pasado y el presente, entre los vivos y los muertos. Esto también lo identificó Pilar Riaño en su estudio sobre las memorias de los jóvenes pertenecientes a las bandas juveniles de la zona nororiental de Medellín (Riaño, 2000), un sector de la población muy golpeado por la violencia, que con sus prácticas re-significa la vida diaria y lucha contra la rutinización y banalización de la muerte.

De igual manera, los devotos del cementerio, inmersos en una dura situación social, exaltan la memoria de personajes públicos que impugnaron el orden social, víctimas y mártires por su actividad, oponiéndose al silencio y a la resignación, manteniendo vivo su recuerdo y confiriéndoles la calidad de milagrosos por su obra impugnadora y su sufrimiento. Los cultos a estos personajes surgen en una área considerada museo nacional, lo cual los relaciona con la memoria colectiva y con los imaginarios sobre el pasado, el presente y el futuro. Ubicados en un lugar de la memoria, permiten que el cementerio, lejos de ser un no lugar (Augé, I994), sea primordialmente un lugar identitario y de pertenencia, a pesar de que sus fieles no posean allí la tumba de un ser querido o un mausoleo, sino que lo visiten ocasionalmente sin otro compromiso que el que establecen con las ánimas.

Pero no es sólo la atracción de los milagros lo que mueve al creyente en su visita al cementerio; para muchos éste es un espacio de paseo y reposo donde las angustias encuentran alivio al descargarse sobre las tumbas. Observar atentamente cada nicho, los epitafios, perderse entre los mausoleos prestando atención a los detalles de las estatuas, sentarse y mirar lo que otros hacen procura una sensación de bienestar, y algunos lo hacen no sólo los lunes, sino también como paseo con la familia los 


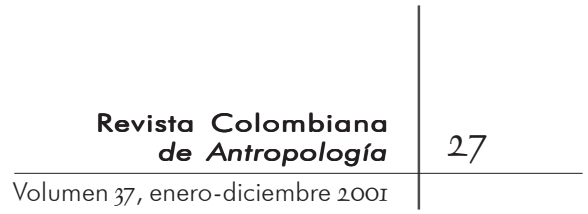

domingos, día en que pueden tomarse fotos al pie de los mausoleos de algunos famosos. Hablar con los muertos, llorar mientras se les cuentan las penas, meditar en los problemas, abrirse a cualquier desconocido y compartir las preocupaciones son beneficios que procuran un desahogo emocional importante para quienes no tienen manera de descargar sus conflictos ni encontrar un consuelo o una esperanza de resolverlos. Este ámbito permite, en una elaboración simbólica, recrear las penosas situaciones de vida de los creyentes, que en su mayoría pertenecen a sectores populares, y proyectarlas en el del mito y los rituales.

\section{EL PODER DE LO NUMINOSO}

Undamentalmente lo QUE Permite Al Cementerio Central - convertirse en un lugar numinoso por excelencia es que es el recinto donde se encuentra la muerte. De la muerte sólo tenemos certeza por la existencia de seres muertos, difuntos que en la concepción religiosa perviven como ánimas. El cementerio es el lugar terreno donde habitan las ánimas, allí se concentra el poder y el misterio que afrontan los seres de ultratumba. Hacer uso de este poder y beneficiarse de él es la base que anima el pensamiento mágico que da lugar a los ritos.

Como espacio numinoso, siguiendo la definición de este concepto de Rudolf Otto (Cazeneuve, I97I), los creyentes lo asumen con la ambivalencia que caracteriza este estado: de un lado es impuro y aterra; de otro es poderoso y fascina. El poder de los espíritus y el mundo sobrenatural se alcanza y manipula por medio de los ritos; el celebrante usa en su beneficio el poder que emana de los muertos. Las flores que se compran a la entrada del cementerio para repartir entre las tumbas de las ánimas que se visitan y a las que se les pide algo adquieren cierto poder después de haberse colocado sobre la lápida. Es por eso que los creyentes acostumbran dejar sus flores y tomar otras que encuentran para llevárselas a la casa. Dicen que colocándolas en la puerta impiden que entren los ladrones, o que guardándolas en el monedero traerán dinero. Otros, en cambio, dicen que los objetos -flores o papeles- que han estado en contacto con las lápidas pueden ser peligrosos y prefieren dejarlos en el cementerio. Es corriente que algunos lleven allí prendas de personas a 


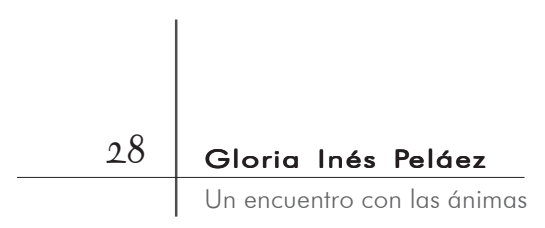

las que quieren hacer daño y las pongan junto a las tumbas o introduzcan en ellas fotografías; así, por medio de ritos de magia negra, procuran causar la muerte de su dueño. La lógica de tal procedimiento descansa en uno de los principios de la magia que señala Frazer: todo lo que el mago haga con un objeto material afectará de igual modo a la persona con quien este objeto estuvo en contacto, haya o no formado parte de su propio cuerpo, ley que el autor denominaba magia contaminante (Frazer, 1993).

Como el poder que emana de los muertos también es usado en beneficio personal, es posible encontrar creyentes que buscan huesecillos de las manos para portarlos en el cuello como amuletos. Hace algunos años, antes de que se remodelara el cementerio, donde se encontraban las fosas comunes y después un basurero existía la práctica de excavar fosas profundas en la tierra, donde los creyentes se introducían para realizar algunos ritos. En medio de restos de ataúdes, lápidas y desechos improvisaban nichos para proteger las velas del viento. La incomodidad y la tierra suelta y pantanosa no eran impedimento para que permanecieran enterrados allí unos minutos, rezando y alumbrando imágenes. Porque lo monstruoso, lo que causa mayor desagrado, facilita el manejo de lo numinoso. El asombro ante tales prácticas revela el pavor que suscita el contacto con la muerte; de allí que para los creyentes que practicaban tales ritos, en tanto más desagradable y espantosa fuera su situación más efectivas eran sus prácticas.

\section{UN ENCUENTRO CON LAS ÁNIMAS}

ADA I DE NOVIEMBRE, DÍA DE LAS ÁNIMAS, LA CELEBRACIÓN SE TOMA las naves del cementerio y en su interior se vive una fiesta. Algunas agremiaciones que poseen mausoleos para sus afiliados citan a sus miembros y éstos, como una obligación con los suyos, deben acompañar a los muertos en ese día. En algunas oportunidades, el licor anima el rato durante el que festejan con sus compañeros. Los muertos viven, aunque de otra manera, y con ellos se establece una comunicación particular; de no ser así, no podría ejercerse el intercambio de bienes y servicios que permite la relación ventajosa para los dos mundos: el de los vivos y el de los muertos. 


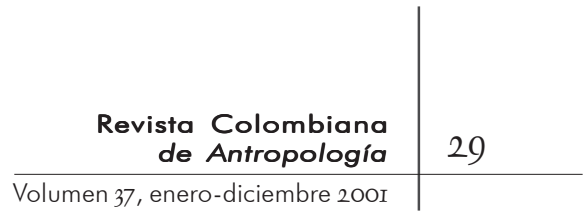

Todos los visitantes, tanto los de los fines de semana como los de los lunes, día especial de visita por ser el día indicado por el ritual, participan de la creencia en el ánima sola o más desamparada y a ella, de preferencia, dirigen sus oraciones. Las almas penan, sufren, ¿quiénes mejor que ellas comprenden los sufrimientos y quiénes más que ellas necesitan de las oraciones de los vivos para terminar su purgatorio? Es común ver a los creyentes pasearse entre las tumbas buscando una que presente rasgos de abandono para acercarse y pedirle con devoción la solución a un problema; le dejan una flor, el consuelo de una oración y la promesa de volver durante los ocho lunes siguientes para completar la novena. O, simplemente, les basta caminar entre las tumbas rezando a todas. La comunicación con las ánimas se establece como si se tratara con un ser vivo: al llegar a la tumba se dan golpes sobre ella en señal de llamado y saludo, se le entregan las flores colocándolas sobre la lápida o se colocan en los floreros, se dejan encima, a veces en forma de cruz; si no se llevan flores se arreglan y riegan las que se encuentran allí. Se enciende el manojo de velas de cebo y se rezan las oraciones. $\mathrm{Al}$ marcharse pueden tomarse algunas flores, no las que se han llevado; se apagan las espermas frotándolas, haciendo cruces sobre la tumba y se dan algunos golpecitos en señal de despedida.

La devoción a las ánimas es muy milagrosa pero requiere cierto cuidado, pues si no se cumplen las novenas, tal y como se promete y lo exige el ritual, pueden enojarse. La comunicación con ellas está moldeada por unos pasos, pero existe cierto margen en el que los creyentes crean sus propias celebraciones y animan a otros para que los imiten, dándose espacios momentáneos de improvisación. Por lo regular las mujeres son quienes propician la devoción a determinadas tumbas e indican en voz alta a quienes se les acercan cómo cumplir las reglas del ritual. Ellas inducen al culto a las ánimas y aconsejan visitar otras tumbas para solucionar sus problemas. La transmisión del conocimiento de algunos ritos se da de manera soterrada y son pocas las personas que hablan abiertamente con desconocidos sobre ellos; por lo regular debe mediar una amistad o parentesco para que se den indicaciones de cómo usar el poder de los muertos. Otros conocimientos se transmiten libremente, siempre y cuando no sirvan para hacer daño a nadie.

Las prácticas mágicas en torno de las ánimas se observan 


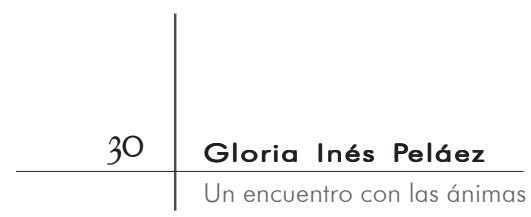

también en el cementerio del Sur de Bogotá. Allí existe un nicho, de una pared completa, donde los creyentes queman las espermas, que para estos rituales deben ser de cebo y se venden con ese fin. Así mismo, en las llamas de las espermas queman monedas amarradas a alambres para procurarse suerte y dinero -práctica muy extendida también en el cementerio Central-. Esta práctica es permitida por la administración que tiene un espacio para colocar placas de agradecimiento por los favores recibidos. Pero a diferencia del cementerio Central, el del Sur no ha dado lugar a personajes milagrosos ni sus prácticas son tan visibles, debido quizás a que le falta el prestigio de una zona histórica, logrado en el Central por los personajes de la vida nacional que reposan allí, así como por la atmósfera especial que brindan sus estatuas y mausoleos.

En el Central una mujer se postra en el prado junto a un mausoleo y busca entre las hierbas; alguien le pregunta qué hace y ella responde que espera encontrar un trébol de cuatro hojas, que encontrado en el cementerio es doblemente poderoso. De inmediato hay varios creyentes gateando por el prado en busca de tal amuleto. Así pueden pasar varios minutos hasta que alguno se cansa y se retira, lo que harán los demás después de un tiempo. Quien no lo vio no sabrá que es posible y ese gesto no se repetirá jamás.

Frente al mausoleo de la familia Kopp, donde una estatua de bronce representa a un hombre pensativo y sus fieles creen ver en ella la figura de su milagroso, "don Leíto", una mujer esparce agua entre los devotos que hacen fila y esperan hablarle al oído para contarle sus penas. La mujer obliga a todos a que se arrodillen y a que caminen así hasta llegar a la estatua; mientras se desplazan con gran dificultad, ella les tira el agua bendita que ha traído en una botella y reza a grandes voces. Promete volver cada lunes y anuncia a los creyentes que recibirán su bendición de nuevo.

Sobre una tumba, una mujer despacha su ritual de conjuro de monedas, pide a quienes se acercan que le faciliten una, y si le dan una de baja denominación dice con algo de enojo: "Si lata da, lata le llega"; luego las toma entre sus manos y las agita dando golpes con su puño sobre la loza. Cierra los ojos e implora al ánima. Las devuelve y espera otra moneda en pago por su conjuro. Los creyentes guardan la suya temerosos de perderla, pues eso les acarrearía mala suerte. 

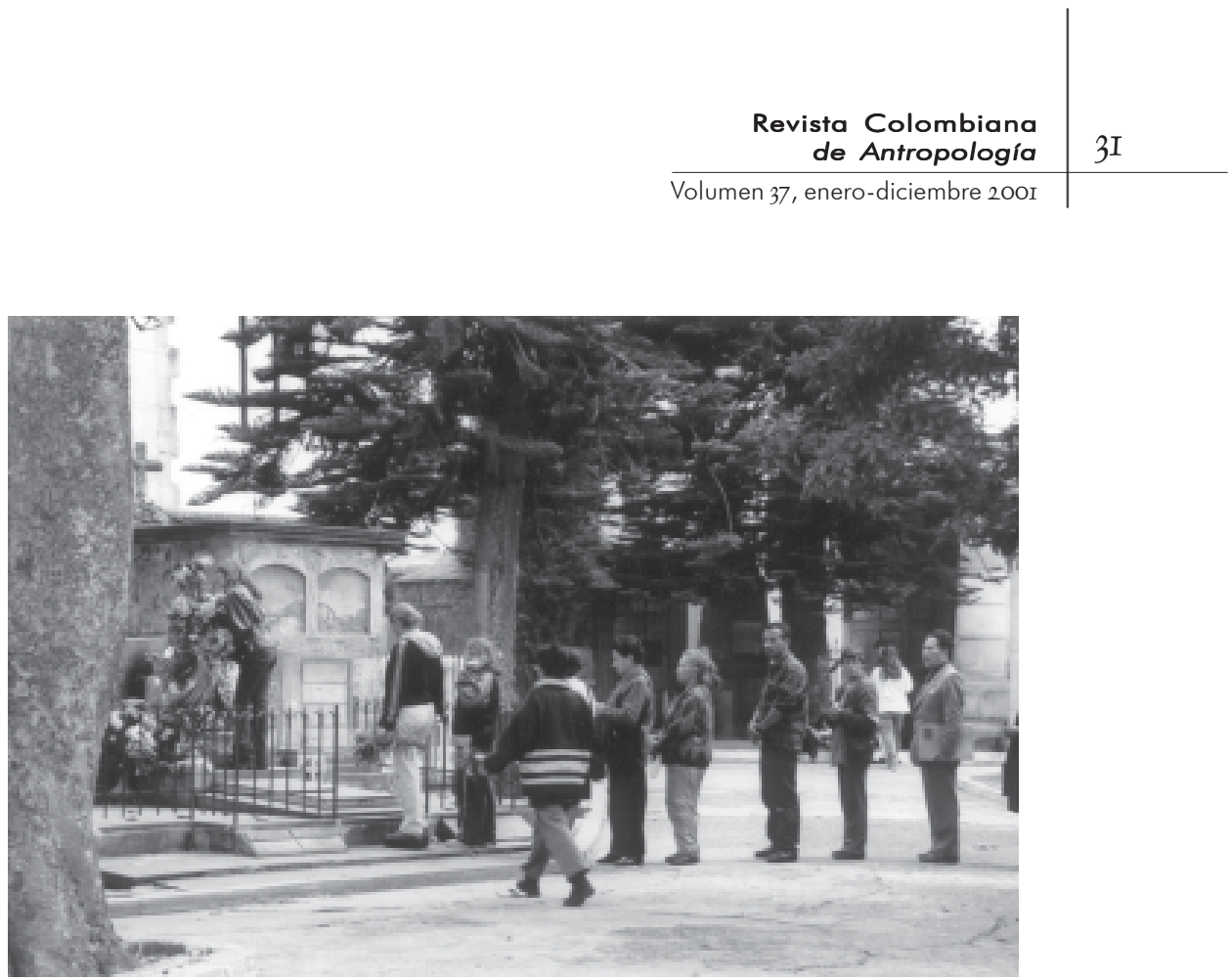

Fieles frente al MAUSOleo de Leo KopP en el CEMENTERIo Central de Bogotá

Otra mujer se pasea por el cementerio y se arroja desesperada sobre una tumba, golpea en ella y llora mientras cuenta al ánima, entre gritos, su problema; una joven se encuentra detrás de ella y la cuida. Es su hija, quien la acompaña con los ojos llorosos. La mujer se levanta y camina unos pasos, luego se prende a las rejas de un mausoleo donde un vitral muestra la figura de la Virgen. De rodillas y aferrada a las rejas se desahoga y le suplica. Después de unos minutos se levanta y juntas continúan el recorrido, más calmadas. Nadie parece extrañarse de sus muestras de dolor ni revela curiosidad por su patetismo.

Un hombre se sube con dificultad al pedestal de la estatua del señor de la salud, colocada a la entrada del cementerio, en la nave central. Representa a Jesús en los brazos abiertos de María, luego de su muerte en el calvario. Imagen parecida a la Pietá de Miguel Ángel. Los creyentes no se alarman y continúan rezando ante la estatua, alzan sus manos portando espermas encendidas y colocan flores en las manos de la Virgen.

Lentamente, el hombre se coloca en la misma posición y sobre el cuerpo del crucificado, como si la Virgen los estuviese sosteniendo a ambos. Luego se queda inmóvil, haciendo equilibrio sobre los contornos irregulares, sin temor de ser quemado por las llamas. Nadie protesta por lo que pudiera ser una profanación, parece que rezaran al hombre que ha tomado el gesto de Jesús. 


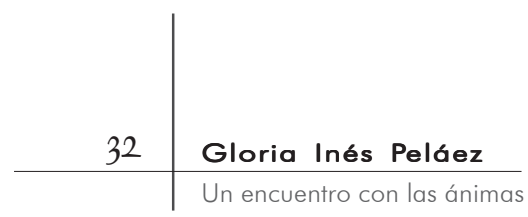

Ningún acto parece desmedido, en cualquier momento alguien puede inventar un ritual o expresar su devoción de la manera que considere conveniente a su necesidad. No hay asombro ni censura, porque en el fondo lo que hacen estos creyentes es una maximización del sentimiento del grupo. Sus acciones permiten a los demás satisfacer sin compromiso consciente sus propios deseos. A semejanza del chamán, siguiendo a Devereux (Devereux, I973), ellos son como todo el grupo, pero más que todo el grupo.

\section{SALOMÉ Y LOS SANTOS POPULARES}

L DESCUBRIMIENTO DE PERSONAJES MILAGROSOS EN EL CEMENTERIO

- Central tuvo lugar en la década de I950, durante el periodo - conocido en Colombia como La violencia. En un sector del cementerio -que era fosa común y donde inhumaban a los muertos anónimos, al que llevaron sin contemplaciones y en volquetadas a los muertos que recogieron de las calles el 9 de abril de I948-, en ese lugar donde se resumía la situación social, un hombre atraído por una cruz sencilla se acercó a rezar. Adquirió la costumbre de acercarse a esa tumba a pedirle un favor. Según respondió a quienes le preguntaron por qué le llevaba flores caras, esa ánima era milagrosa y le estaba pagando un milagro. Una descripción de ese primer devoto lo muestra como un hombre sencillo, apenas distinguible por su ruana, lo cual hace presumir que era de extracción campesina. Aquella fosa, distinguida entre las demás, fue aglutinando personas y la creencia de que en efecto hacía milagros conformó una incipiente feligresía que también aseguró haber recibido favores.

Cuatro años más tarde apareció una mujer que dijo ser la hija de la milagrosa, a quien dio el nombre de Salomé viuda de Parra. Poco tiempo después, otra mujer, que fue descrita como la dueña de un prostíbulo, aseguró ser también familiar de la milagrosa y peleó con quien decía ser hija de la muerta. Al fin llegaron a un acuerdo y se retiró para dejar a la familia Parra en posesión del culto.

Tales acontecimientos, aunque lejanos en el tiempo, aún reposan en la memoria de algunos marmoleros que tienen su negocio contiguo al cementerio y han escuchado a sus padres 


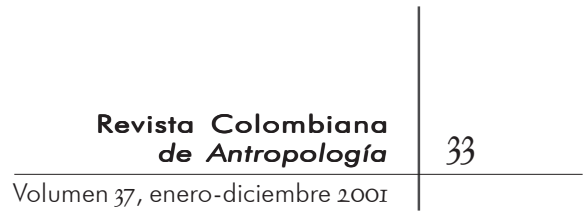

contar la historia (Peláez, I982). Dicen que los que aseguraron ser familiares de la milagrosa -de los cuales dudan, e incluso ponen en entredicho la existencia de los restos de una mujer llamada Salomé-, comenzaron a vender la foto de la santa impresa en papelitos borrosos, así como su oración, y se pusieron al frente de los devotos, recogiendo sus limosnas. Cuando tuvo una feligresía considerable, el hombre que descubrió a la milagrosa pagó con su dinero un lote en la nave central del cementerio, en el sector de los ex presidentes, y los restos fueron trasladados allí. En un mausoleo parecido a una capillita romana, con un metro cuadrado de base por dos y medio de altura -cubierto totalmente por placas de mármol de agradecimiento-, había una alcancía que recogía las dádivas de los devotos cuando su nieta no se encontraba presente, pues vendía espermas a la entrada del cementerio.

La presencia de Salomé en la nave central y su corte de devotos acrecentó la idea de descubrir otros milagrosos; entonces cundió la fiebre por rezar a otras ánimas solas y desamparadas con el afán de pedir más favores. Así aparecieron otras milagrosas que tuvieron corta vida de milagros y fueron olvidadas; otras no y con el tiempo conformaron un grupo de milagrosos, ubicados todos cerca de Salomé. De esta manera surgieron Mercedes e Inés, dos hermanas contiguas a la tumba de Salomé; también hicieron parte de este grupo Leo S. Kopp, José Raquel Mercado y Gustavo Rojas Pinilla.

Durante mucho tiempo, los fieles de Salomé tuvieron la oportunidad de saber por boca de su hija quién fue ella y de averiguar las razones de su santidad; sin embargo, las versiones que se tienen sobre la vida y la muerte de la milagrosa difieren entre sí y no concuerdan con la versión de los que se dijeron eran sus familiares, porque la identidad de la santa la construyeron sus devotos. Todas las situaciones que los creyentes atribuyen a Salomé tienen que ver con el trabajo, la familia y sus penosas condiciones de vida, encontrándose referencias crueles a la violencia que padeció en estos órdenes. Sus fieles elaboraron su vida, dejando a un lado la versión simple y elemental de sus familiares, que contaban de ella que era una mujer muy buena que murió de una enfermedad de los riñones. Para sus devotos, en cambio, el sufrimiento, la violencia y la miseria hacen de Salomé una víctima, encontrándose estas características en todas las versiones que tienen sobre ella. Cada relato que se dice 


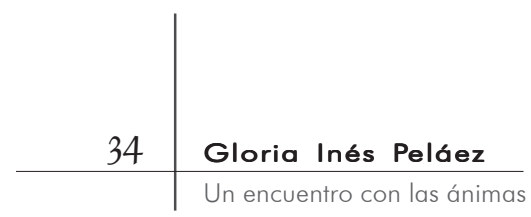

de Salomé es parte de la vida de sus devotos, quienes han proyectado su realidad social y los conflictos que les son inherentes. Pero no es sólo percibida como víctima, también es rebelde al presentarla como prostituta, siendo esta una de las versiones más generalizadas, por lo que no es extraño que una parte de sus devotas practiquen este oficio y consideren a la milagrosa como su protectora.

Pero como Salomé es víctima de un orden, así también lo fueron los otros personajes: Rojas Pinilla, Mercado y Kopp, que se elevaron a la categoría de milagrosos. Todos han dirigido una institución y fueron víctimas de una violencia exterior que los convirtió en mártires. La violencia que los agredió provino de un orden existente, el cual ellos trataron de impugnar: los personajes de vida pública por medios institucionales y Salomé como prostituta, atentando contra la moral tradicional. Se puede afirmar de manera general que los milagrosos estuvieron fuera de la norma y, en esta medida, impugnaron un orden.

Como en otros cementerios se presentan casos de milagrosos que en vida fueron antisociales o guerrilleros, podemos considerar que la existencia del arquetipo del héroe (Eliade, I982) está implícita en la configuración de estos santos. Así también se convierten en héroes sus devotos, quienes elevan a tal categoría a estos personajes, identificándose con su actividad impugnadora. De hecho, los fieles hacen caso omiso de las formas religiosas institucionales, omitiendo toda representación institucional -sacerdotes- y creando sus propios cultos.

El número de visitantes de los lunes, día de visita, la imposibilidad de controlar sus actividades y los reclamos de los propietarios de los mausoleos, afectados por el tizne de las espermas, llevaron a que en I980 la administración del cementerio Central acabara con estos cultos populares. El cementerio se cerró por un tiempo y se le hicieron algunos cambios. Las tumbas de Inés y Mercedes se alteraron, otras se cercaron y se colocaron rejas exteriores que intentaron alejar a los visitantes. Por un tiempo para entrar al cementerio se pidieron papeles o el carné que acreditaba la posesión de una tumba y se requisó para que no se introdujeran espermas. Se encargó el estudio histórico de los personajes importantes en la historia nacional que yacían en la nave central y se colocaron vallas para señalar el lugar donde se encontraban. Pero el cambio más importante fue el traslado de Salomé 


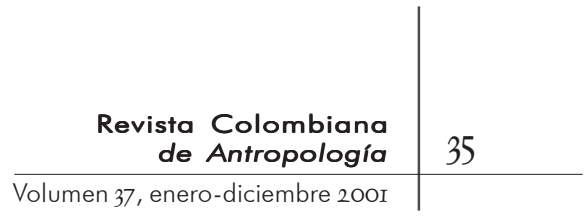

al cementerio del Sur, donde se ofreció a sus familiares un sitio a cambio del que tenía junto a los ex presidentes. De esta manera fue llevada al sur, con sus devotos, pues las acciones que aquí eran censuradas allá no incomodaban a los muertos, afines a su condición social.

\section{UNA MILAGROSA POPULAR}

A LGUNOS CREYENTES CONTINÚAN ASISTIENDO AL LUGAR DONDE SE ENcontraba la tumba de Salomé, sin saber que ella no está allí, Mllevados por el ejemplo de otros que se detienen y rezan, colocan flores y espermas. Unas pocas palabras bastan para que se amplíe la feligresía; los nuevos devotos no necesitan una historia o una justificación de por qué esa ánima es milagrosa, basta con saber que concede favores para contar con su asistencia semanal. Trasladada al cementerio del Sur hace veinte años, el mausoleo donde se encontraba Salomé dejó como única huella un rectángulo de cemento al que por un tiempo la gente adornó con flores. Contigua a este mausoleo hay una tumba sin nombre que posee solamente una cruz; a ella le confirió su cualidad de milagrosa y hoy es el sitio donde se reúnen algunos de sus fieles, convencidos de que en ese lugar se encuentra la madre Salomé, como la llaman. Las versiones que existen hoy sobre la identidad de la milagrosa son las mismas que se tenían antes de su traslado al sur; el culto continúa igual, a pesar de que sus devotos desconocen su ausencia.

La mujer que decía ser la nieta de la milagrosa ya no oficia en el cementerio Central y las propagadoras de su culto son las creyentes que cuentan a otras o dan ejemplo a quienes se acercan por primera vez y preguntan tímidamente. En el cementerio del Sur tiene una nueva feligresía que desconoce el origen de su santificación en el cementerio Central. Sus restos se encuentran en una tumba sencilla y sin nombre, cubierta por pequeñas placas de mármol en agradecimiento por favores recibidos. De la superficie de la tumba se desprende una loza que lleva inscrita la "Oración a Salomé”. Sus fieles la levantan, la leen y vuelven a colocarla. El culto no necesita de alguien que lo promueva u oficie ya que continúa sin la presencia de quienes se dijeron eran sus familiares. Los lunes no le faltan las flores ni las espermas encendidas, 


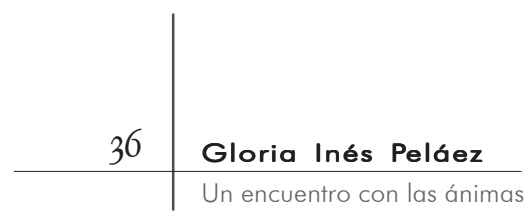

las cuales protegen del viento haciendo nichos con ladrillos que permanecen a su lado. Ubicada entre dos galerías en un muro lateral, se reconviene a los devotos para que no se limpien las manos ni apaguen las espermas en ellas.

La oración a Salomé se vende a la entrada del cementerio del Sur y es la misma que tenía cuando se encontraba en el Central; sólo unos pequeños cambios muestran cómo ha sido reescrita varias veces para su impresión. Su texto es el de una oración tradicional y puede reconocerse claramente que ha sido tomado de otras oraciones. En uno de sus apartes dice:

La iglesia empero, os ha honrado en todas las ocasiones, os ha tenido siempre en privilegiado sitio en la gloriosa escala de los santos mantenedores de la fe cristiana, os ha invocado como universal patrona de casos desesperados porque vuestra clemencia se ha movido dadivosamente para enjugar las lágrimas amargas de quienes padecen mucho y mucho han de menester. Rogad por mí que soy tan miserable.

A la oración la acompaña la fotografía borrosa de una mujer de edad avanzada, que tiene sus manos unidas sobre el vientre, en uno de sus brazos lleva colgado un pañolón y tiene puesto un sombrero propio de las campesinas boyacenses. Esta es la única imagen que se conoce de Salomé, que muestra el origen popular de su culto y las razones por las cuales una milagrosa de origen humilde se convierte en protectora de los necesitados, fieles que en un principio debieron llegar del campo a Bogotá y crearon su propia santa, proyectando en ella sus condiciones de vida y dotándola de las características que les sugería su propia experiencia.

\section{RAZONES DE LOS MILAgROSOS}

OCOS CREYENTES SE PREGUNTAN LAS RAZONES POR LAS CUALES EL PERsonaje milagroso posee tal cualidad. Para ellos basta con que la experiencia de los otros se lo confirme o que alguien les diga que hace milagros para que, sin otro cuestionamiento, lo acepten como verdad. Planteado de ésta manera, el porqué un personaje hace milagros es más un problema del investigador que del creyente. La pregunta lleva a que el devoto aduzca la 


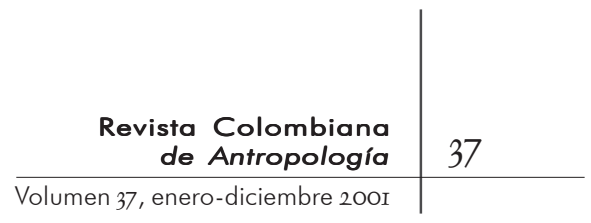

necesaria ayuda de la fe, sin la cual no existen los portentos, presente como prueba la fe colectiva y el testimonio de los demás o, simplemente, responda que porque así es.

Corresponde al investigador trazar un recorrido con preguntas indirectas sobre lo que el creyente considera que fue la vida de su milagroso y las causas de su muerte, así como indagar sobre las condiciones de vida de aquel que cree. Sólo así es posible entender las razones por las cuales en el cementerio Central se consideran milagrosos personajes de la vida y la historia nacional como José Raquel Mercado y Gustavo Rojas Pinilla y, últimamente, han ingresado en el panteón, producto de acontecimientos más recientes, Carlos Pizarro Leongómez -comandante del reinsertado Movimiento M-I9-, Jaime Pardo Leal -dirigente de la extinguida Unión Patriótica- y Álvaro Gómez Hurtado -dirigente del Partido Conservador-. A pesar de provenir de diferentes vertientes de la política, en vida todos ellos impugnaron el orden establecido y fueron víctimas del mismo orden al que se opusieron. Considerados héroes y mártires, son intermediarios ante Dios para la resolución de favores; a cambio reciben oraciones y flores.

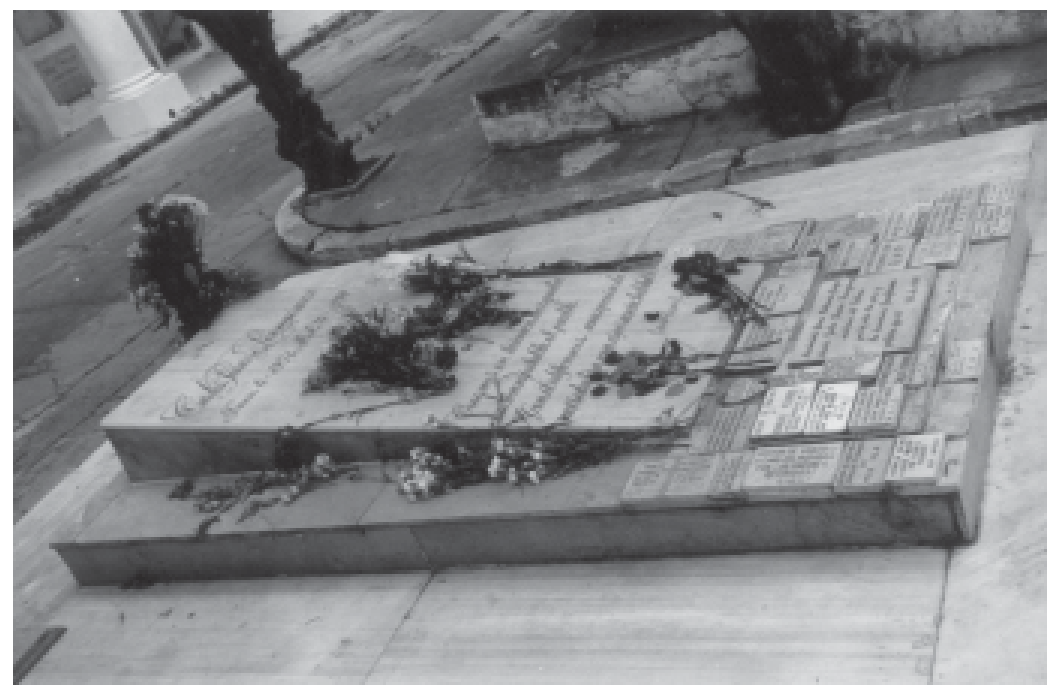

Tumba de Carlos Pizarro LeongómeZ en el CEMENTERio Central de Bogotá 

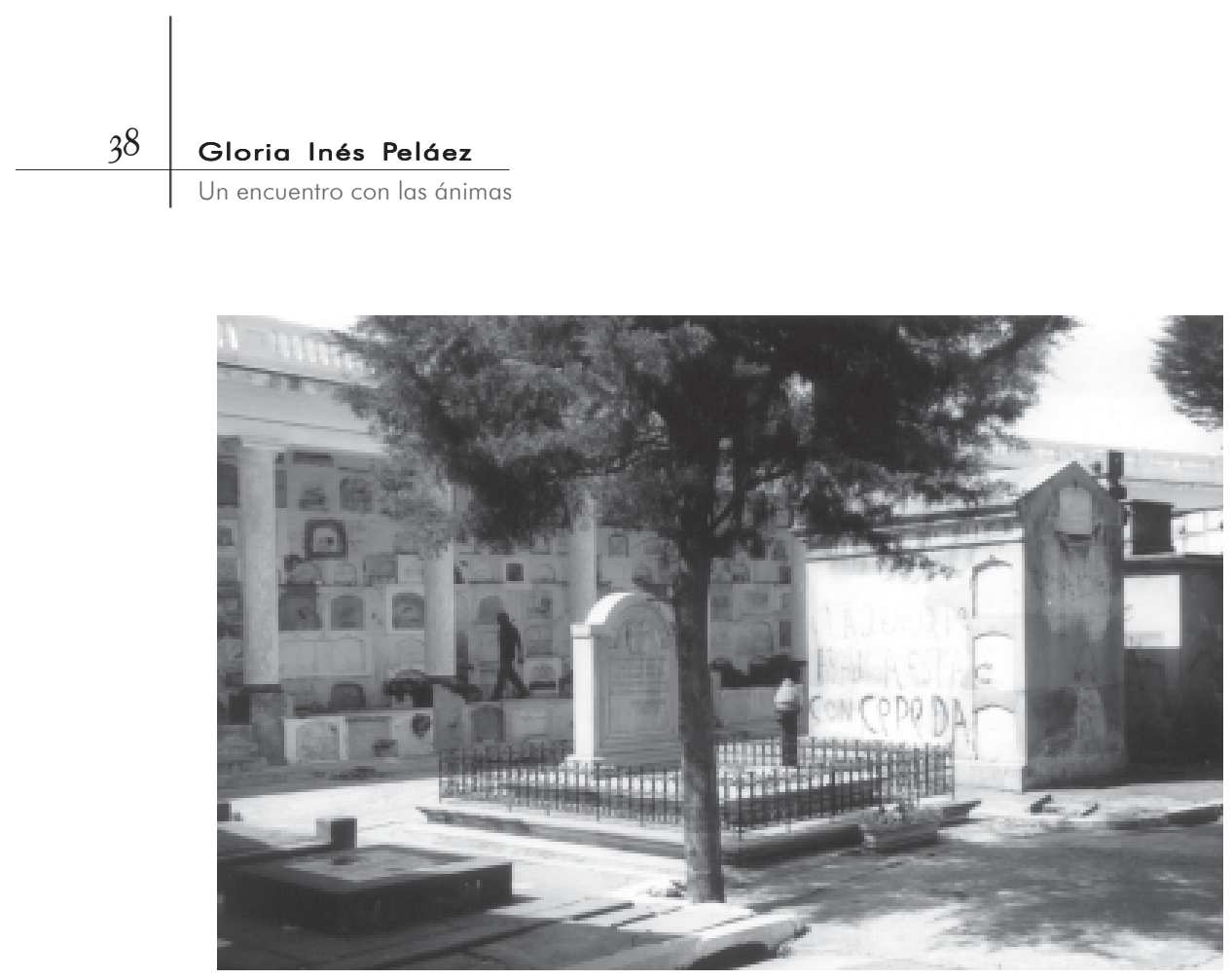

Tumba de Jaime Pardo Leal en el cementerio Central de Bogotá

Sin embargo, no todos los que se acercan a rezar ante sus tumbas tienen presentes los acontecimientos reales de sus vidas; otras razones dan cuenta de su carácter milagroso, entre otras, la atribución de una extrema maldad, ya que necesitan más que otros de las oraciones y la atención de los vivos para salir del purgatorio. Sobre sus lápidas, los epígrafes resumen los ideales que sin duda los llevaron a la muerte; los visitantes los leen y depositan su ofrenda y no dejan de golpear la loza antes de marcharse. Algunos creyentes no entienden su significado y desconocen la actividad pública de algunos. No importa, no atienden las razones de la política, pero si otros les llevan flores y les rezan es que hacen milagros, lo confirman las placas de agradecimiento que adornan las tumbas. La lápida sencilla de Álvaro Gómez, sin epígrafe ni leyenda que rescate su memoria, es marcada con los débiles trazos de un lápiz por creyentes que necesitan la figuración de su líder y contar a otros lo que ha hecho, renovando de esta forma sus votos de adhesión. Incluso alguien, para ser reconocido por el difunto, escribió el número de su cédula, recordando tal vez la práctica electorera de recoger las cédulas en las elecciones.

Después del luctuoso año de I990, cuando murieron o fueron asesinados gran parte de los personajes hoy también milagrosos 


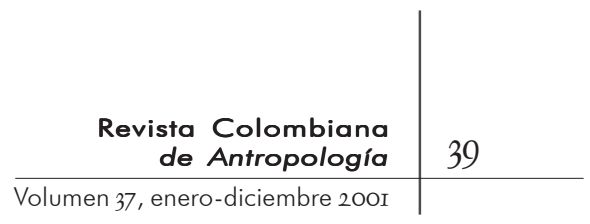

en el cementerio Central, las paredes de los pabellones se han llenado de consignas. Escritas en los muros cercanos a las tumbas, introducen en el cementerio un discurso que, en términos políticos, destaca el valor de la lucha de estos impugnadores del statu quo y reconoce su carácter de héroes. Un discurso que manifiesta por medio de la consigna política lo mismo que expresa el devoto cuando le rinde culto. Ambos elevan a la condición de milagroso e inmortal a un impugnador de la norma que muere víctima de su obra opositora. Tanto el devoto como el activista político le aseguran su lealtad y reconocimiento.

\section{LO FEMENINO EN LA SIMBÓLICA}

A PRIMERA VISITA OBLIGADA DE LOS CREYENTES CUANDO INGRESAN AL cementerio Central es al señor de la salud. Los brazos de María extendidos reciben a su hijo agonizante y su gesto no se ha cerrado, permanece detenido porque es la madre -la muerteque recibe a aquellos que han de vivir en el mundo de los muertos y que llegarán a ella buscando la paz y la regeneración. La muerte de los hombres, representada en Jesús, es superada, franqueada por un nuevo renacer en María, la madre. El señor de la salud revive, en tanto que simboliza la fundición con la madre y este símbolo de vida está ubicado a la entrada del cementerio.

El influjo de lo femenino en su calidad de generador, guardián de la vida y protector se observa en la inclinación de los creyentes por designar como mujeres a las ánimas que son milagrosas y no tienen nombres sobre sus tumbas. Así ocurrió cuando se inició la creación de los santos populares en el cementerio Central (Peláez, 1982). Cuando los marmoleros recibían el encargo de hacer placas de agradecimiento y colocarlas sobre las tumbas anónimas las bautizaban con nombres de mujeres. Todo lo que se relaciona con Salomé tiene que ver con el ámbito de la mujer en la familia y el trabajo. A ella van a pedírsele favores que alivien problemas domésticos o mal de amores, preferentemente. Como se dijo, para un grupo de sus feligreses Salomé es la patrona de las prostitutas.

Aunque la presencia de hombres que van a rezar a las ánimas es considerable, teniendo en cuenta el número de devotos que asisten cada lunes al cementerio, las mujeres tienen una parte 
más activa en la propagación del culto y lideran las celebraciones espontáneas junto a las tumbas. Las indicaciones de cómo deben hacerse las novenas, los relatos sobre las bondades de los milagrosos, el cuidado voluntario de las flores depositadas sobre los lugares del culto -riego y arreglo de floreros- están a cargo de las mujeres. Una devota se encarga de mantener limpia y brillante la estatua de bronce de Leo Kopp. Usualmente han sido mujeres las que tienen las ventas de objetos necesarios para el culto en la entrada del cementerio; allí ofrecen los manojos de espermas de cebo, los ramilletes de flores, los cirios, las novenas de las almas del purgatorio y las de otros santos, las oraciones con que se hacen prácticas mágicas -la de san Cipriano, la mano poderosa-. Cualquier oración que busque un devoto la tienen ellas, así como imágenes y exvotos.

\section{El CEMENTERIO COMO UNA CIUDAD}

UEDE CONCLUIRSE QUE EL CEMENTERIO NO ES SÓLO UN ESPACIO MÁGIco-religioso, que además de ser un importante lugar de peregrinación es fuente de identidad e historia. Es un espacio público donde lo privado - la tumba, los recuerdos de familia, los restos, la propiedad, las ofrendas, los problemas y las necesidades personales- se hacen públicos para el uso y servicio de otros visitantes y necesitados; es un centro de contacto e intercambio de bienes y servicios. En un intercambio ritual, el creyente se comunica con los muertos y aunque no vaya con la intención de encontrar un beneficio material en los favores que estos le puedan conceder, sí logra descargar su angustia y conseguir un momento de paz, para lo cual sólo le basta un paseo entre las tumbas. La situación social de los devotos de los personajes milagrosos está presente en la representación religiosa que anima su culto, dotando a sus santos de características afines con su experiencia vital -Salomé-, y con su deseo resuelto simbólicamente de alzarse también contra la norma, como sus héroes -Pizarro, Rojas Pinilla, Pardo Leal-. 


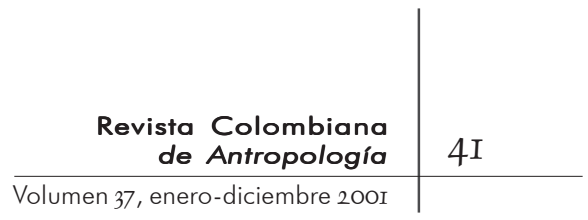

\section{Bibliografía}

Augé, Marc. 1994. Los no lugares. Gedisa. Barcelona.

Calvo, Óscar Iván. I998. El cementerio Central: Bogotá, la vida urbana y la muerte. Tercer Mundo Editores-Observatorio de Cultura Urbana. Bogotá.

Cazeneuve, Jean. 197i. Sociología del rito. Amorrortu. Buenos Aires.

Devereux, Georges. 1973. Ensayos de etnosiquiatría general. Seix Barral. Barcelona.

Eliade, Mircea. 1982. El mito del eterno retorno. Alianza-Emece. Buenos Aires.

Frazer, James. 1993. La rama dorada. Magia y religión. Fondo de Cultura Económica. México.

Lombardi, Satriani. I975. Antropología cultural; análisis de la cultura subalterna. Galerna. Buenos Aires.

Peláez, Gloria Inés. 1982. "Religiosidad popular; estudio sobre los santos del cementerio Central". Universidad Nacional de Colombia. Monografía de grado. Bogotá.

1994. "Magia, religión y mito en el cementerio Central de Santafé de Bogotá". En Pobladores urbanos. Tercer Mundo Editores-ICAN. Bogotá.

Rank, Отто. El mito del nacimiento del héroe. Paidós. Buenos Aires.

Riaño, Pilar. 2000. "La memoria viva de las muertes. Lugares e identidades juveniles en Medellín”. En Análisis político. Universidad Nacional de Colombia-IEPRI. 4I. SeptiembreDiciembre.

Ricoeur, Paul. I976. Introducción a la simbólica del mal. Editorial Megápolis. Buenos Aires.

Villa, María Eugenia. i993. Muerte, cultos y cementerios. Editores Disloque. Bogotá. 